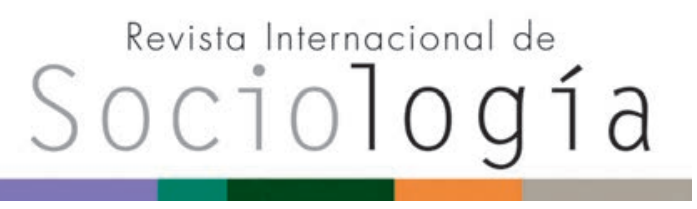

Revista Internacional de Sociología RIS

vol. 77 (2), e126, abril-junio, 2019, ISSN-L:0034-9712 https://doi.org/10.3989/ris.2019.77.2.17.022

\section{LA INNOVACION SOCIAL, ¿PRÁCTICAS PARA PRODUCIR AUTONOMÍA, EMPODERAMIENTO Y NUEVA INSTITUCIONALIDAD?}

\author{
Rubén Martínez Moreno \\ Universidad Autónoma de Barcelona \\ ruben@lahidra.net \\ https://orcid.org/0000-0002-0620-8406 \\ Helena Cruz Gallach \\ Universidad Autónoma de Barcelona \\ helena.cruz@uab.cat \\ https://orcid.org/0000-0002-0494-6923 \\ ISMAEL BLANCO \\ Universidad Autónoma de Barcelona \\ ismael.blanco@uab.cat \\ http://orcid.org/0000-0003-2191-5712 \\ YunaILIS SALAZAR \\ Universidad Autónoma de Barcelona \\ yunailis.salazar@uab.cat \\ https://orcid.org/0000-0001-7630-9758
}

Cómo citar este artículo / Citation: Martínez Moreno, R, H. Cruz Gallach, I. Blanco y Y. Salazar. 2019. "La innovación social, ¿prácticas para producir autonomía, empoderamiento y nueva institucionalidad?". Revista Internacional de Sociología 77(2):e126 https://doi. org/10.3989/ris.2019.77.2.17.022

\section{Resumen}

A partir del análisis del caso de Cataluña, este artículo contribuye al debate en torno a la innovación social, ofreciendo una visión general sobre el desarrollo de las prácticas socialmente innovadoras y preguntándose por su potencial transformador en tres dimensiones: 1) la creación de espacios de autonomía social; 2) el empoderamiento ciudadano (particularmente de colectivos y en territorios de especial vulnerabilidad social), y 3) el desarrollo de nuevas arquitecturas institucionales que promuevan y refuercen los derechos sociales y de ciudadanía. El artículo parte de una extensa investigación que ha combinado el mapeo de la innovación social, una encuesta online y distintas entrevistas semi-estructuradas con informantes clave. En el artículo se muestran las potencialidades y los límites de la innovación social como factor de transformación social y se señala, asimismo, la necesidad de crear las condiciones institucionales propicias para su generalización y su consolidación.

\section{Palabras Clave}

Barrios; Crisis; Empoderamiento; Innovación social.
SOCIAL INNOVATION, PRACTICES TO PRODUCE AUTONOMY, EMPOWERMENT AND NEW INSTITUTIONALITY?
Copyright: @ 2019 CSIC. Este es un artículo de acceso abierto distribuido bajo los términos de la licencia de uso y distribución Creative Commons Reconocimiento 4.0 Internacional (CC BY 4.0).

Recibido: 09/02/2017. Aceptado: 29/11/2018 Publicado online: 04/06/2019

\section{Abstract}

Based on an analysis of the Catalunya case, this article contributes to the ongoing debate on social innovation, offering a general vision of the development of socially innovative practices and looking into its transforming potential in three key areas: 1) creation of social auton-omy spaces; 2) citizen empowerment (especially within communities/ collectives and in high social risk/vulner-ability areas) and 3) development of new institutional ar-chitectures that would promote and reinforce social as well as citizen rights. The article forms part of an exten-sive investigation that has combined social innovation mapping, an online survey and various semi-structured interviews with key informants. The article outlines the potential and limitations of social innovation as a factor of social transformation, and thus points out the need for creation of favourable institutional conditions for its spread and consolidation.

\section{KEYWORDS}

Crisis; Empowerment; Neighbourhoods; Social innovation. 


\section{INTRODUCCIÓN}

Vivimos tiempos inciertos marcados por las consecuencias de una crisis estructural y multidimensional. Si observamos el momento actual, no parece que estemos frente a una crisis coyuntural cuyo cierre pueda resituarnos en el punto inicial. Hablar del carácter multidimensional de la crisis conlleva reconocer que, más allá del modelo económico, lo que hoy está en cuestión es nuestra forma de participar en la vida pública, las formas de relación entre las instituciones políticas y la ciudadanía e, incluso, los valores éticos y morales que están en la base de nuestros comportamientos sociales.

La crisis se percibe tan profunda y compleja que la innovación se nos presenta como un imperativo. Sin embargo, a pesar de la relevancia explicativa de la crisis, la construcción de la innovación como elemento clave para la bonanza económica tiene un largo recorrido en el contexto europeo, siendo, en realidad, uno de los elementos fundacionales de la Unión Europea (UE) en su etapa contemporánea. A principios del año 2000, en el Consejo Europeo extraordinario de Lisboa ${ }^{1}$, la innovación fue mencionada por primera vez como línea estratégica de la UE, relacionándola con "la importancia creciente de las tecnologías de la información y la comunicación en las esferas profesionales y privadas". En el Programa Marco Horizonte 2020, la Comisión Europea ha vuelto a remarcar la importancia de la innovación económica, la innovación administrativa y la innovación social, así como los ciclos de retroalimentación que se producen entre éstas. Pero, ¿de qué tipo de proceso se está hablando cuando se alude a la innovación? ¿De dónde se espera que surjan tales innovaciones? ¿Qué contenidos y qué alcance se espera que tengan? ¿Qué factores pueden contribuir a su cristalización?

En este artículo ponemos la atención en la innovación social, con el objetivo de contribuir a un debate que ha ido tomando una importancia creciente en España, así como en Europa y en otras partes del mundo. A partir de un análisis centrado en el caso de Cataluña, pretendemos ofrecer una visión general sobre el desarrollo de las prácticas socialmente innovadoras, poniendo especial énfasis en tres cuestiones que nos permiten calibrar su potencial transformador. En primer lugar, el artículo se pregunta por el espacio que, en un contexto de crisis y austeridad como el actual, ocupan las iniciativas de innovación social con respecto al mercado y a los poderes públicos: ¿en qué medida dichas iniciativas configuran un espacio singular y autónomo con respecto al sector público y al sector mercantil? ¿Qué significación tiene dicho espacio en el presente contexto de crisis? En segundo lugar, el artículo cuestiona la medida en que dichas iniciativas generan dinámicas de empoderamiento ciudadano, especialmente de colectivos y en territorios de especial vulnerabilidad social: ¿es la innovación social un catalizador de procesos de empoderamiento de los colectivos y en los territorios más vulnerables? ¿Cabe esperar que la innovación social actúe como un elemento favorecedor de la inclusión y la cohesión social? El último interrogante hace referencia a la capacidad de estas iniciativas para generar nueva institucionalidad democrática, es decir, arquitecturas institucionales que promuevan, refuercen y amplíen derechos sociales y de ciudadanía. Este último aspecto depende de factores como las formas organizativas de la innovación social, su sostenibilidad y su escalabilidad: ¿Son las iniciativas socialmente innovadoras espacios altamente participativos? ¿Son capaces de sostenerse en el tiempo y de escalar territorialmente más allá del ámbito microlocal?

Para dar respuesta a estas preguntas, partimos de los datos generados por una investigación realizada en los últimos años en Cataluña, en la que se han combinado tres grandes tipos de herramientas metodológicas: la elaboración de un Mapa de la Innovación Social en Cataluña ${ }^{2}$; la realización de una encuesta online a las iniciativas identificadas en el mapa, y el desarrollo de diferentes entrevistas con académicos, activistas sociales y responsables públicos.

En la primera parte del artículo, realizamos un breve repaso de los diferentes prismas conceptuales desde los que se ha ido construyendo la noción de la innovación social. Es en el marco de este repaso de la literatura que señalamos el significado y la importancia de las preguntas principales que abordamos. En el segundo apartado, se explica el alcance de la innovación social en que se basa esta investigación, el tipo de iniciativas identificadas en el Mapa, el método con que ha sido elaborado y otros detalles relativos a la muestra y al diseño de la encuesta y de las entrevistas. En el tercer, cuarto y quinto apartado, explicamos los principales resultados del estudio, estructurados a partir de las tres preguntas planteadas. Por último, cerramos el artículo con una sección de conclusiones en la que contrastamos los resultados con los debates internacionales sobre la innovación social.

\section{LA INNOVACIÓN SOCIAL: UN BREVE REPA- SO DE LOS ORÍGENES Y LA EVOLUCIÓN DEL CONCEPTO}

Si bien se suele subrayar como un concepto de origen reciente, los significados y prácticas que han sido descritas bajo el prisma conceptual de la innovación social parten de un debate iniciado hace dos siglos (Godin 2008). Sin ignorar esa trayectoria histórica, pero centrándonos en sus usos actuales, vemos que durante los últimos años diversos organismos y programas públicos han destacado la innovación social como un proceso que es necesario fomentar, especialmente en tiempos de crisis (Brugué, Blanco y Boada 2014). 
En marzo del 2000, con la celebración del Consejo Europeo Extraordinario de Lisboa subtitulado "hacia la Europa de la Innovación y el Conocimiento", la innovación se introduce por primera vez como línea estratégica de actuación de la UE. El concepto toma fuerza a partir de la comunicación de la Comisión Europea de marzo de 2003, tras constatar que los objetivos innovadores de la Agenda de Lisboa de 2000 habían tenido un cumplimiento muy desigual. Promoviendo una visión más amplia de la innovación, algunas críticas cuestionan la concepción reflejada en el Manual de Oslo, una de las principales directrices para definir y ofrecer protocolos para optimizar los procesos de $\mathrm{I}+\mathrm{D}+\mathrm{i}$ en la industria europea (NESTA 2006; Stirling 2015). Una revisión de las definiciones y métricas, desde la primera edición del Manual de Oslo (OECD 1997) hasta la tercera (OECD 2005), muestra la paulatina ampliación de los espacios donde se considera que emerge o se produce innovación. Dejando atrás la centralidad tecnológica del primer Manual, las siguientes versiones enfatizan la importancia de los procesos de comercialización, los cambios organizativos y el potencial de innovación latente que emerge desde un todo social en prácticas extraeconómicas que desbordan los muros de las empresas. En este giro social de la innovación es importante destacar también la función ejercida por organismos como el National Endowment for Science Technology and the Arts, think tank británico que ha denunciado la incapacidad de las métricas europeas para captar la innovación oculta, aquélla basada en procesos cooperativos de base social (NESTA 2006; 2007).

La innovación social cuenta con un recorrido previo tanto en el ámbito de investigación aplicada como en las políticas públicas más allá del continente europeo, habiendo sido promovida por organizaciones como el Centro de Innovación Social de Stanford o en el informe del Conseil de la Sciencie et la Technologie de Quebec del año 2000. Ejemplos de la importancia que toma la innovación social en el ámbito de las políticas públicas a partir de la crisis económica son la Office of Social Innovation and Civic Participation del Consejo de Política Nacional de la Casa Blanca, fundada en 2009, o el programa The Big Society, puesto en marcha por el entonces primer ministro británico David Cameron a finales del mismo año. Entre sus principios, la Office of Social Innovation destaca la necesidad de crear nuevos líderes comunitarios, nuevas formas de colaboración público-privada y "el fomento del servicio como una solución y una manera de desarrollar el liderazgo de la comunidad"3. The Big Society fue un concepto paraguas para enmarcar una serie de medidas con la intención de dar mayor protagonismo y capacidad de decisión a las iniciativas de voluntariado, comunidades locales, líderes comunitarios y emprendedores sociales.
Haciéndose eco de esta concepción social de la innovación, la cual pone el acento en su valor público y en las relaciones sociales cooperativas a través de las que se produce, la propia Comisión Europea ha contribuido de una manera decisiva a la popularización de esta noción en el continente europeo en los últimos años. Su definición se basa en el trabajo The Open Book of Social Innovation (Murray, Caulier-Grice y Mulgan 2010:3), en el cual la innovación social se describe como "nuevas ideas, productos, servicios o modelos que satisfacen las necesidades sociales (con mayor eficacia que las alternativas) y que a su vez crean nuevas relaciones sociales o colaboraciones". Como ejemplos de innovación social, la Comisión Europea enumera "los planes de prevención de la cardiopatía coronaria que se dirigen a toda la comunidad, en lugar de hacerlo únicamente a las personas «de riesgo»; las redes sociales de vecinos que ayudan a personas mayores que viven solas; los eco-mapas urbanos que ofrecen a las comunidades locales información sobre sus adelantos en la consecución de los objetivos de reducción de emisiones; o los bancos éticos que proporcionan productos financieros con el fin de maximizar la rentabilidad social y medioambiental de las inversiones" (Bureau of European Policy Advisers 2010:24).

Según un informe del Bureau of European Policy Advisers (2010), organismo vinculado a la Comisión Europea, las innovaciones sociales: "son innovaciones que son sociales tanto en sus fines como en sus medios (...). Concretamente, definimos las innovaciones sociales como nuevas ideas (productos, servicios y modelos) que simultáneamente satisfacen necesidades sociales (más efectivamente que sus alternativas) y crean nuevas relaciones o colaboraciones sociales. En otras palabras, se trata de innovaciones que no sólo son positivas para la sociedad, sino que también refuerzan la capacidad de acción social" (ibid. 2010:24).

Siguiendo esta misma definición, se remarca que la innovación social está orientada "no sólo a desarrollar soluciones innovadoras, sino también nuevas formas de organización y de interacción para abordar temas sociales" (ibid. 2010:26).

Uno de los autores que más influencia ha tenido a nivel europeo es Geoff Mulgan, actual director del NESTA. Para Mulgan, existen múltiples ejemplos que ilustran cómo aquellos procesos que se entendían en los márgenes del desarrollo económico ocupan hoy un lugar destacado. Entre otros, señala las "guarderías cooperativas vecinales y las patrullas de barrio; Wikipedia y la Open University; la atención integral de la salud y los hospicios; los microcréditos y cooperativas de consumo; el movimiento para el comercio justo; el desarrollo de viviendas que no emiten carbono y las granjas comunitarias; la justicia restaurativa y los tribunales comunitarios; los grupos online de autoayuda para problemas de salud" (Mulgan 2006:146). 
Según Mulgan, estas innovaciones son gestionadas y transformadas en productos o servicios por individuos que "tienen que capturar la imaginación de una comunidad de seguidores, mediante la combinación del coraje contagioso y la persistencia pragmática" (ibid. 2006:153). Del mismo modo que en las concepciones clásicas de la innovación económica (Schumpeter 1934, Mulgan describe a sujetos individuales que, empujados por motivaciones personales y caracterizados por ser "intérpretes competentes de sus propias vidas y con capacidad resolutiva de sus propios problemas" (ibid. 2006:150), lideran los procesos de innovación social. Mulgan ejemplifica estos perfiles de emprendedores con nombres como Octavia Hill, inventora de ideas para la gestión de la vivienda, la protección del patrimonio y la vivienda comunitaria; el sociólogo y activista Michael Young, fundador de Young Foundation y de la Open University; o Muhammad Yunnus, fundador del Grameen Bank y otras empresas de microcrédito.

En sintonía con las ideas de Mulgan, Charles Leadbeater, asesor y colaborador de organismos influyentes en las políticas públicas que fomentan la innovación, como DEMOS y NESTA, comparte esa misma orientación. Para Leadbeater, hay dos motivos por los cuales es necesario fomentar la innovación social desde las políticas públicas. El primero es que puede "responder más eficazmente a una serie de problemas sociales para los que el Estado de bienestar no está preparado para hacer frente" (Leadbeater 1997:12). En segundo lugar, hay un argumento relacionado con la sostenibilidad del propio estado del bienestar: "Todas las sociedades con sistemas de protección social desarrollados están destruyendo lentamente los derechos históricos de bienestar, en un intento para reducir sus costes (...) La innovación es la única esperanza que tenemos de mantener la calidad del bienestar y reducir sus costes. Un sistema de bienestar innovador y eficiente tiene que poder hacer más para contribuir a la salud económica de la sociedad en su conjunto" (ibid. 1997:13). Estas aportaciones permiten entender el enfoque económico de la innovación social, puesto que hacen hincapié en el papel que se le otorga para dar respuesta a la crisis, no sólo económica, sino a una crisis institucional de carácter sistémico. Desde este enfoque, la idea básica que se defiende es que, si el Estado ya no puede responder a las múltiples demandas sociales, la propia sociedad es quien tiene que auto-organizarse para resolverlas. En la lógica que preside este enfoque, estas prácticas no tienen por qué venir acompañadas de un cambio en las relaciones de poder o de un cambio institucional para ser consideradas como innovación social, sino que lo esencial radica en su capacidad para resolver problemas concretos a través de nuevos productos o servicios.

Un enfoque alternativo es el que Oosterlynck et alii llaman "el enfoque de base de la innovación so- cial", el cual la define como "aquellas prácticas circunscritas en ámbitos locales (...) que ayudan a los excluidos sociales y a las personas y grupos sociales empobrecidos a satisfacer necesidades sociales básicas para las cuales no encuentran soluciones adecuadas ni en el mercado privado ni en las macro-políticas de bienestar" (Oosterlynck et al. 2013: 2). EI proyecto SINGOCOM ${ }^{4}$, coordinado por Frank Moulaert y financiado por la Comisión Europea, ha contribuido de manera decisiva a la teorización de este enfoque (véase Moulaert et al. 2010). En su definición, "la innovación social ocurre cuando la movilización de fuerzas sociales e institucionales logra la satisfacción de necesidades humanas previamente alienadas, el empoderamiento de grupos previamente silenciosos o excluidos a través de la creación de nuevas capacidades y, en último término, la transformación de las relaciones sociales (y de poder) existentes hacia un sistema de gobernanza más democrático e inclusivo" (González, Moulaert y Martinelli 2010:54). Para SINGOCOM, las variables territoriales y sociales, así como las trayectorias institucionales que facilitan o dificultan los contextos con capacidad de responder a demandas colectivas, son centrales a la hora de entender un proceso de innovación social. Este enfoque de la innovación social como producción social que incide y, a la vez, depende de su contexto socio-espacial e institucional contrasta con las concepciones más economicistas, que tienden a observarlo como un fenómeno individual, espontáneo y replicable.

En general, y a modo de síntesis, podemos diferenciar dos enfoques de la innovación social a partir de lo hasta ahora señalado y de contribuciones de otros autores (Martínez Celorrio, 2015; Conejero y Redondo, 2016). Estas dos perspectivas son deudoras de tradiciones diferentes que explican el cambio en procesos de crisis poniendo énfasis en sujetos individuales que abren nuevos mercados y facilitan la colaboración o en prácticas de acción colectiva que transforman los imaginarios sociales y las relaciones de poder. En primer lugar, el enfoque económico-managerial, que define la innovación social combinando la lógica de mercado con la creación de relaciones sociales y dando especial protagonismo al sujeto económico emprendedor (Leadbeater 1997; Mulgan 2006). En segundo lugar, el enfoque que podemos denominar institucional-territorial, en el que la innovación social se define como prácticas y procesos a través de los que las comunidades excluidas responden a necesidades básicas y, transformando las relaciones de poder, conquistan capacidades que les otorgan mayor autonomía (Moulaert 2010; Oosterlynck et al. 2013). Analizando procesos de transformación social, este segundo enfoque, centrado en los estudios sobre gobernanza y desarrollo territorial, dialoga con las teorías del cambio social y de la acción colectiva. 
De la revisión de toda esta literatura se derivan tres cuestiones centrales en el debate sobre el qué, el cómo y el para qué de la innovación social, cuestiones a las que dedicamos lo que resta de la discusión teórica de este artículo y el análisis empírico subsiguiente.

La primera cuestión hace referencia a la capacidad de las iniciativas ciudadanas para configurar un espacio socialmente autónomo, articulado al margen de los poderes públicos y de los mercados. Uno de los grandes argumentos en pro de la innovación social es justamente la creciente relevancia de las prácticas cooperativas entre la ciudadanía como respuesta al retroceso del sector público y a la intensificación de las dinámicas excluyentes del mercado laboral, energético, residencial, alimentario, etc. en el contexto de la crisis. La propia literatura, sin embargo, asume que las fronteras intersectoriales son a menudo difíciles de establecer, al reconocer el potencial que ciertas iniciativas socialmente innovadoras pueden tener para el mercado y al asumir el papel que las políticas públicas pueden jugar en la activación, el sostenimiento y el reescalamiento de las innovaciones sociales (Moulaert 2010). El análisis empírico de los orígenes de las iniciativas, de sus objetivos y de su significación social en el contexto en el que emergen se vislumbra como un primer tema clave.

El segundo tema que consideramos central en la discusión sobre la innovación social es su capacidad para activar dinámicas de inclusión y de empoderamiento entre los colectivos y los territorios más vulnerables. Ésta es una cuestión central para autores como Moulaert (2010) y Oosterlynck et al. (2013), quienes incluyen el empoderamiento de los excluidos y la transformación de las relaciones de poder como dos rasgos fundamentales de este tipo de iniciativas. La visión mainstream de la innovación social, como la defendida por las instituciones europeas, acostumbra a obviar el poder disruptivo de estas iniciativas, es decir, su capacidad para alterar relaciones de poder entre colectivos sociales y entre áreas urbanas. Y, sin embargo, el valor de la innovación social entre los grupos y en los territorios más vulnerables es remarcado por la mayor parte de la literatura, al ser en estos espacios territoriales y sociales donde más evidentes son las limitaciones de la actuación pública y del mercado y donde más dramáticas son sus consecuencias. Surge así la pregunta, que merece ser contrastada empíricamente, sobre la capacidad de las iniciativas de innovación social de generar transformaciones significativas de los colectivos y los territorios de mayor vulnerabilidad, contribuyendo a la creación de sociedades más inclusivas y cohesionadas.

La última cuestión fundamental en el debate hace referencia a su capacidad para generar nueva institucionalidad democrática (Blanco, Fleury y Subirats 2012), es decir, nuevas arquitecturas insti- tucionales que promuevan, refuercen y amplíen los derechos sociales y de participación entre la ciudadanía (Martinelli 2013). La capacidad de la innovación social para lograr este cometido está íntimamente ligada al carácter participativo, la sostenibilidad y la escalabilidad de las iniciativas. El carácter más o menos participativo de los espacios de innovación social determina su potencial contribución al desarrollo de nuevos espacios democráticos. Por sostenibilidad entendemos la capacidad de dichas iniciativas de mantenerse en el tiempo, evitando su disolución una vez se debilita o desaparece el empuje de un núcleo impulsor. Por escalabilidad se entiende la capacidad de las iniciativas de innovación social de trascender el ámbito microlocal de actuación en el que surgen habitualmente (el barrio o incluso entidades territoriales o grupales más pequeñas), creciendo hacia escalas territoriales más amplias o replicándose en otros colectivos o territorios. En parte, esta capacidad de escalar territorialmente depende de los apoyos por parte de los poderes públicos, quienes pueden jugar un papel clave en la promoción, expansión y consolidación de estas prácticas.

\section{Metodología: MAPEO, ENTREVISTAS Y EN- CUESTA ON-LINE}

De la discusión teórica planteada emerge una batería de preguntas cuya respuesta nos permite conocer con más profundidad la naturaleza y el potencial transformador de las prácticas emergentes de innovación social (tabla 1). Tales preguntas se agrupan en las tres dimensiones analíticas clave que acabamos de señalar (autonomía social, empoderamiento y nueva institucionalidad) y nos remiten, más concretamente, a aspectos como los orígenes, los objetivos, la magnitud social, las bases socio-espaciales, las formas organizativas, los horizontes temporales y la escalabilidad de las iniciativas de innovación social.

Para responder a estas preguntas, nos basamos en una investigación realizada en Cataluña que ha tenido como objetivo fundamental ofrecer una visión panorámica de las prácticas de innovación social en esta región, contrastando así esta realidad empírica con los debates teóricos sobre la cuestión. Esta investigación se fundamenta en el uso combinado de tres herramientas principales de recolección de datos: el mapeo de la innovación social, una encuesta y la realización de entrevistas semi-estructuradas. Del análisis cartográfico y de la encuesta extraemos aquellos indicadores señalados en la tabla 1 que nos permiten obtener información significativa para las distintas preguntas que, a modo de variables, identificamos en la misma tabla. Las entrevistas semi-estructuradas tienen como misión principal ayudarnos a interpretar en su contexto las informaciones obtenidas a través del mapa y de la encuesta online. Todo ello se explica con más detalle a continuación. 
Tabla 1.

Modelo de análisis del valor transformador de la innovación social en Cataluña

\begin{tabular}{|l|l|l|}
\hline \multirow{2}{*}{ Dimensiones de análisis } & Variables & Indicadores \\
\hline \multirow{2}{*}{ Autonomía social } & Objetivos & Objetivos declarados \\
\cline { 2 - 3 } & Origen & Origen social o institucional de la iniciativa \\
\cline { 2 - 3 } & Magnitud & Número de personas que las componen \\
\hline \multirow{2}{*}{$\begin{array}{l}\text { Empoderamiento de grupos y territorios } \\
\text { Nueva institucionalidad democrática }\end{array}$} & \multirow{2}{*}{ Bases socio-espaciales } & $\begin{array}{l}\text { Localización respecto al grado de vulnerabilidad social de las } \\
\text { Sorbanas }\end{array}$ \\
\cline { 2 - 3 } & \multirow{2}{*}{ Organización } & $\begin{array}{l}\text { Grado de participación interna } \\
\text { Inserción en redes interorganizativas }\end{array}$ \\
\cline { 2 - 3 } & \multirow{2}{*}{ Escalabilidad } & $\begin{array}{l}\text { Autonomía financiera } \\
\text { Grado de profesionalización }\end{array}$ \\
\cline { 2 - 3 } & Grado de interacción con sector mercantil, asociativo y público \\
Intensidad y tipos de apoyos institucionales públicos
\end{tabular}

En primer lugar, la cartografía de la innovación social en Cataluña incluye más de setecientas prácticas (figura 1). Para elaborar este mapa, hemos utilizado tres fuentes básicas de información:

1) Cartografías ya existentes de modalidades de innovación social. Se han recogido datos georreferenciados y sistematizados de cartografías anteriores, como Los bancos de tiempo y la moneda social en España o el Mapa de huertos urbanos de Barcelona.

2) Datos online. Se han recogido los datos proporcionados por algunas plataformas sociales, por ejemplo, la Plataforma de Afectados por la Hipoteca $(\mathrm{PAH})$, la cooperativa de energía renovable Som Energia (Somos Energía), la cooperativa de servicios financieros Coop 57 y Guifi.net, una infraestructura en red compuesta en su mayoría por redes comunitarias de telecomunicaciones inalámbricas.

3) Un formulario colaborativo. Hemos diseñado un formulario online con el que, tras la posterior validación del grupo de investigación, cualquier persona puede agregar casos a la cartografía. Un centenar de las setecientas prácticas de innovación social se han añadido a la cartografía gracias a la colaboración de colaboradores online ${ }^{5}$.

Los datos extraídos de estas fuentes de información han sido almacenados en una base de datos online cuya visualización está disponible a través de una cartografía de software abierto (Mapbox). Se han utilizado herramientas de cloud mapping que permiten la observación de la densidad espacial de cada una de estas categorías, así como información más específica de cada práctica.

Todos estos datos han sido agrupados en cuatro categorías principales y ocho subcategorías: a) Solidaridad ciudadana: procesos de colaboración ciudadana tales como bancos de tiempo y asambleas locales de la PAH.

b) Territorio, medio ambiente y energía: prácticas relacionadas con el entorno urbano y que fomentan formas más sostenibles de acceso, uso y gestión de los recursos. Se incluyen: huertos urbanos, cooperativas de energía renovable y redes de telecomunicaciones gestionadas comunitariamente.

c) Economía y consumo alternativo: proyectos que fomentan el intercambio horizontal de productos o que promueven espacios de consumo alternativos, incluyendo proyectos financiados por la banca ética, la economía social y solidaria y las cooperativas de consumo de productos agroecológicos.

d) Espacios autogestionados que fomentan la gestión cívica y autónoma: prácticas de gestión comunitaria de edificios y equipamientos en desuso.

Nos centramos en esas categorías y prácticas por ser mencionadas frecuentemente en la literatura como ejemplos típicos de innovación social. Todas ellas representan prácticas horizontales y de cooperación ciudadana que tratan de satisfacer necesidades sociales diversas como la vivienda, la alimentación, la energía y el uso de espacios públicos. Además, pretenden ofrecer alternativas a las formas dominantes de satisfacción de necesidades en el mercado y el sector público. Asimismo, son espacios donde la ciudadanía no sólo pone en práctica formas alternativas de vivir y de interactuar, sino que también formula (de forma más o menos explícita) alternativas sociopolíticas frente al statu quo.

En segundo lugar, con el programa LimeSurvey hemos diseñado una encuesta que se ha distribuido a 
Figura 1

Mapa de la Innovación Social de Cataluña

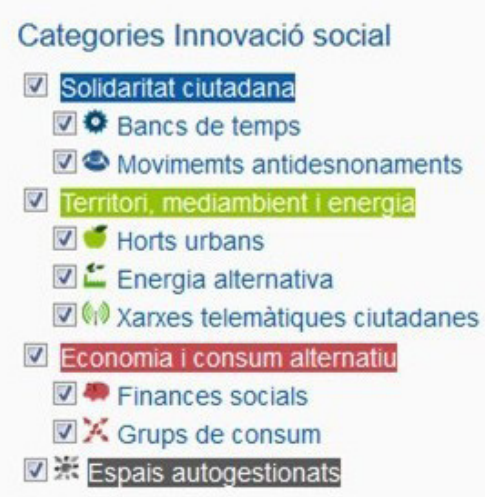

través de correo electrónico a las iniciativas identificadas. De las 710 iniciativas geolocalizadas hasta abril de 2015, conseguimos recoger los correos electrónicos de 529 experiencias, se realizaron 482 envíos satisfactorios y se abrieron el $37,2 \%$ de los correos enviados. Finalmente, se obtuvieron 107 respuestas. El potencial sesgo derivado de la autoselección de los encuestados es elevado. Sin embargo, al comparar la muestra (las encuestas respondidas) con el universo de referencia (el mapa de la innovación social) con base en criterios de distribución temática y territorial, observamos que existe una correspondencia notable entre ambas, lo cual confiere un alto grado de confiabilidad a los resultados de la encuesta ${ }^{6}$.

El cuestionario estaba orientado a obtener información específica de cada una de las experiencias y se organizaba en cinco grandes bloques. En primer lugar, se preguntó por las características generales de la iniciativa (personas implicadas y la existencia de personal contratado) así como por sus objetivos. El segundo bloque hacía referencia al rol de la Administración Pública (grado, duración y tipo de soporte institucional recibido) y al apoyo por parte de entidades del tercer sector. El tercer bloque se dedicó a la organización de las iniciativas. Respecto a la organización interna, se preguntaba por los mecanismos de participación existentes y por el cumplimiento de algunos criterios (equidad de género, integración de grupos vulnerables, integración de personas inmigradas), mientras que, a nivel de organización externa, se preguntaba por las relaciones con otros colectivos (frecuencia, ámbito territorial, pertenencia a redes de entidades, etc.). El cuarto bloque se dedicó a la sustentabilidad de las experiencias, con especial énfasis en sus presupuestos y sus fuentes de ingresos. El último bloque tenía un carácter más prospectivo y pretendía conocer los principales retos que se afrontan en estas experiencias.

En tercer lugar, se realizaron siete entrevistas a diferentes perfiles académicos, profesionales y activistas. Como se ha comentado, el valor principal de estas entrevistas fue el de ayudarnos a contextualizar los resultados obtenidos a través de la encuesta y del mapeo. Las personas a las que entrevistamos tienen, por sus distintos perfiles, una posición privilegiada para la comprensión de las dinámicas de innovación social en Cataluña y, por ello, sus opiniones, en tanto que informantes clave, nos ofrecen una información cualitativa de gran interés para el abordaje de la discusión planteada. Sin duda, el valor informativo de estas entrevistas se ve limitado por su escaso número, pero las horas acumuladas de conversación con estas personas complementan y enriquecen el análisis cartográfico y estadístico realizado. Algunas de las preguntas principales que orientaron estas conversaciones semiestructuradas fueron: ¿Qué motivos explican la creciente presencia de la innovación social en la agenda pública?, ¿Por qué genera tanto interés?, ¿Qué razones motivan las prácticas socialmente innovadoras?, ¿Quiénes las protagonizan?, ¿Cómo funcionan? 
A continuación, exponemos los resultados del análisis cartográfico, estadístico y cualitativo realizado, agrupando las evidencias empíricas en función de las tres preguntas principales en las que se focaliza este artículo, relativas a la autonomía de las iniciativas de innovación social, su capacidad para generar empoderamiento ciudadano y su contribución a la construcción de nueva institucionalidad democrática.

\section{¿UN ESPACIO EMERGENTE DE AUTONOMÍA SOCIAL?}

Como hemos visto, la literatura ha remarcado el valor de la innovación social en un contexto de crisis, en el que se intensifican las dinámicas excluyentes de los mercados y en el que el margen de maniobra de los poderes públicos se ve significativamente restringido. $\mathrm{Si}$ a ello añadimos que esta crisis no parece ser fruto de una coyuntura concreta, sino el reflejo de un nuevo escenario estructural, la importancia de la innovación social como espacio autónomo frente al Estado y al mercado es aún mayor. La investigación permite aproximarnos al análisis empírico a través de una serie de preguntas e indicadores relacionados con los orígenes de las iniciativas socialmente innovadoras, los objetivos que persiguen y su peso social relativo.

Respecto a los orígenes, lo primero que debemos destacar es que la mayoría de las iniciativas identificadas (55 \%) surgen en el periodo 2008-2014 y, muy especialmente, entre los años 2011 y 2012 (27,1\%) (figura 2). Podríamos inferir que la proliferación de este tipo de prácticas en Cataluña guarda una relación significativa con el contexto de la crisis económica y social. Más concretamente, si atendemos al gran número de iniciativas surgidas a partir de 2011, podríamos interpretar que una buena parte de éstas surgen al calor de las movilizaciones sociales del 15M. Si la crisis multidimensional que atravesamos desde el estallido de la burbuja inmobiliaria en 2008 representa un terreno fértil para la innovación social, las movilizaciones del 15M actúan, aparentemente, como la chispa que activa su rápida propagación. Si bien esto resulta confirmado por las impresiones de nuestros entrevistados, los mismos han subrayado que este tipo de iniciativas guardan relación con una importante tradición en Cataluña de autogestión, cooperativismo y luchas vecinales (Andreu 2015; Dalmau y Miró 2013; Observatorio Metropolitano de Barcelona 2013).

Otra cuestión crucial para calibrar las dimensiones del fenómeno es la magnitud de las iniciativas observadas: ¿cuántas personas las protagonizan? ¿Qué volumen de recursos gestionan? Los resultados de la encuesta nos permiten constatar que hablamos en su gran mayoría de iniciativas de pequeñas dimensiones, tanto si miramos las personas que las integran (el $53,3 \%$ no superan las cincuenta personas) como los presupuestos que gestionan (el $38 \%$ gestiona menos de $1.000 €$; el $50 \%$ menos de $5.000 €)$. Cabe matizar que algunas de las iniciativas identificadas en el mapa forman parte de organizaciones sociales de escala supralocal, como es el caso de los nodos de la red telemática Guifi.net, las asambleas locales de la PAH, los grupos locales de Som Energia o los proyectos financiados por Coop57. Como veremos más adelante, este tipo de prácticas acostumbran a mantener relaciones habituales entre ellas, como mínimo a escala local. Esas conexiones contribuyen a compensar la posible fragmentación del mapa de la innovación social.

Hablamos, pues, de pequeños colectivos sociales que pueden formar parte de redes de acción colectiva más amplias, surgidas en su mayoría en el contexto de la crisis y especialmente a partir de la aparición del movimiento $15 \mathrm{M}$. Pero, ¿cuál es su origen?, ¿quién las promueve? En su mayor parte, se trata de iniciativas que nacen desde la ciudadanía, con un elevado grado de autonomía con respecto a las instituciones y a otros agentes privados y del tercer sector. Así, el $66,4 \%$ de las iniciativas se autocalifican como "exclusivamente ciudadanas", un carácter autónomo que es aún más marcado entre las redes telemáticas ciudadanas, el movimiento antidesahucios, los grupos de consumo cooperativo (de energía sostenible y de productos agroecológicos) y los espacios autogestionados (figura 3). Si seguimos con el análisis por categorías, observamos dos excepciones muy significativas: sólo el $45 \%$ de los huertos comunitarios y el $25 \%$ de los bancos del tiempo se autocalifican como iniciativas exclusivamente ciudadanas, mientras que la gran mayoría o bien reconocen haber sido promovidas por las instituciones o bien dicen haber recibido apoyo por parte de las mismas. Ello confirma algo que se puede empezar a observar en los municipios catalanes: la aparición de nuevas políticas públicas que promueven la gestión comunitaria de vacíos urbanos surgidos a partir del estallido de la burbuja inmobiliaria (Blanco et al. 2016) y la promoción de bancos del tiempo como estrategia para promover el intercambio horizontal y no monetario de servicios entre la ciudadanía?.

Figura 2

Año de creación de las experiencias de innovación social

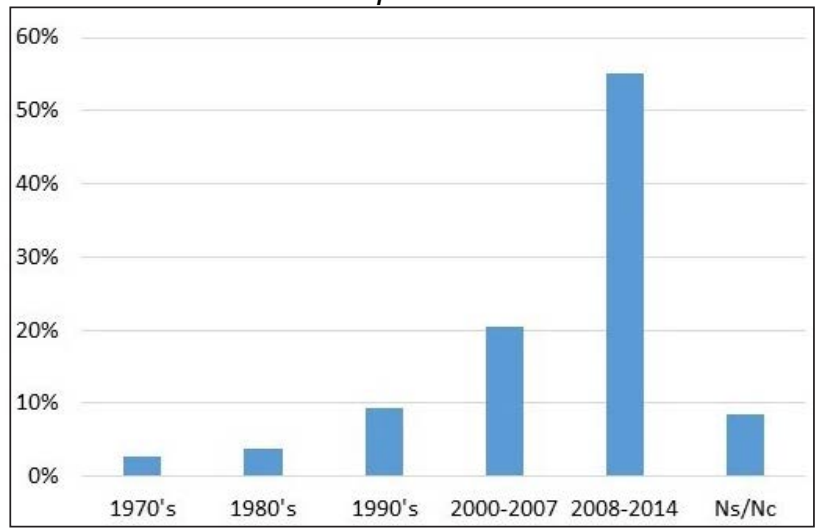

Fuente: Elaboración propia 
Figura 3

Origen de las experiencias de innovación social

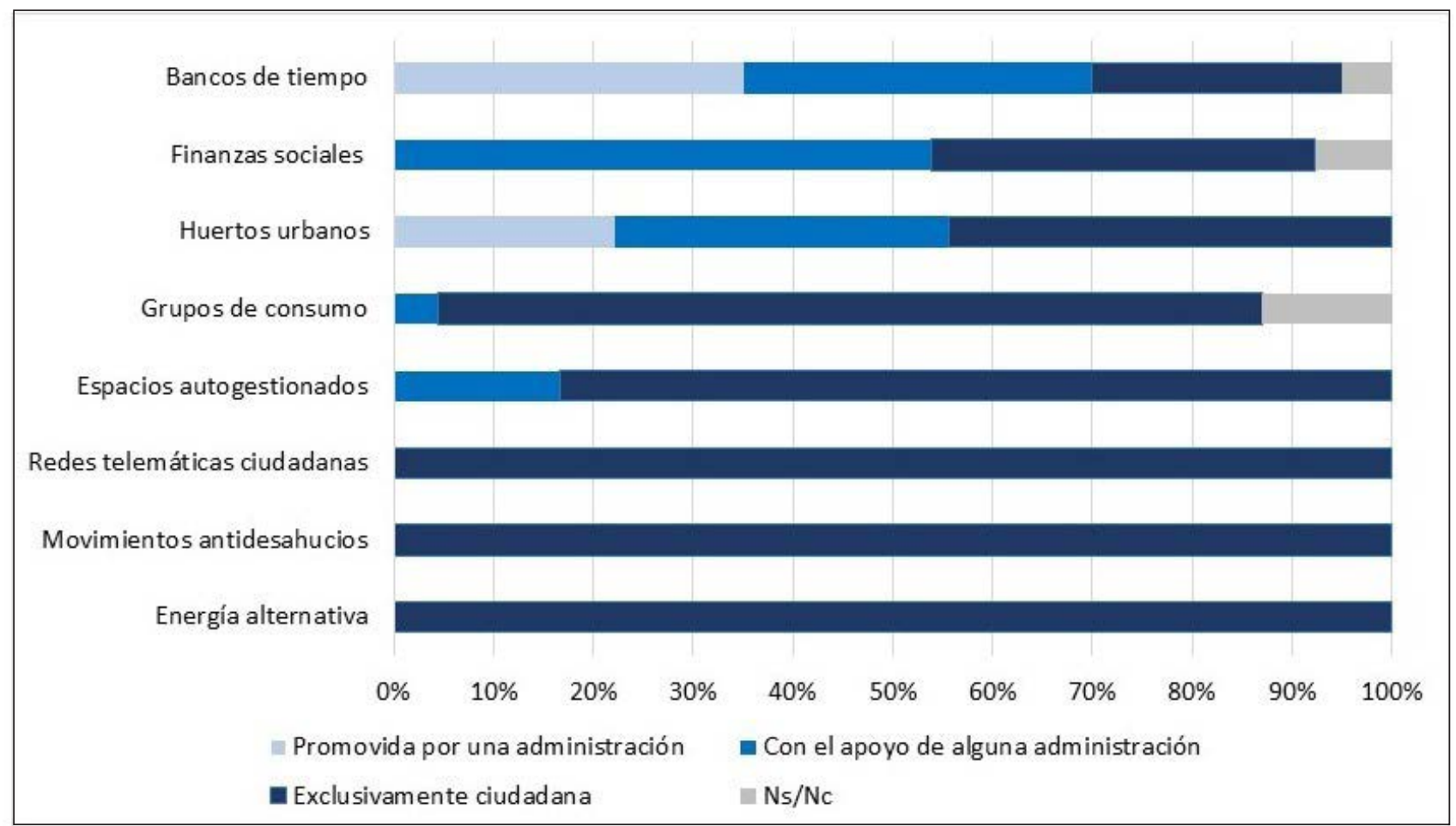

Fuente: Elaboración propia

¿Con qué objetivos se ponen en marcha estas prácticas? Las respuestas indican que la mayoría consideran que uno de sus principales cometidos es reforzar vínculos comunitarios y generar prácticas alternativas a los sistemas dominantes de producción, trabajo, consumo y relación entre las personas (figura 4). Se destaca como objetivo la satisfacción de necesidades colectivas con dimensión social o medioambiental (acceso a las telecomunicaciones, acceso a la vivienda, disfrute de espacios comunitarios, consumo de productos y servicios ecológicos, acceso a crédito para proyectos empresariales y de desarrollo local...). En menor medida, la defensa de derechos sociales y medioambientales se encuentra también entre sus objetivos principales.

Por el contrario, los objetivos menos valorados son la generación de espacios de ocio y el impacto en las políticas. Este último aspecto es relevante, puesto que, junto a la escala con la que acostumbran a operar, representa un punto de diferencia significativo con respecto a los movimientos sociales clásicos, cuyo cometido básico es provocar transformaciones en las formas de operar de los poderes públicos (Tilly 1978; Snow 2004; Martinelli 2013). El tipo de prácticas analizadas no priorizan tener impacto directo sobre las políticas públicas. Antes, su objetivo más valorado es producir o sostener comunidades cuya actividad pue- da satisfacer necesidades básicas que, en último término, promuevan nuevos derechos sociales y ambientales. Una excepción significativa son las asambleas del movimiento antidesahucios, que en todos de los casos destacan la incidencia sobre políticas públicas como objetivo prioritario. En menor medida, también podemos señalar las cooperativas de consumo energético, que en un $85 \%$ de los casos señalan el impacto en las políticas como muy importante.

En resumen, los datos recogidos confirman que la crisis del 2008, y especialmente el surgimiento del $15 \mathrm{M}^{8}$, han catapultado muchas iniciativas como las que analizamos (grupos de consumo cooperativo, espacios autogestionarios, bancos del tiempo, finanzas éticas, etc.). Dichas prácticas tienen, en su mayoría, una fuerte vocación por mantenerse en tanto que espacios socialmente autónomos y, de hecho, ni tan sólo mencionan el impacto en las políticas públicas como uno de sus objetivos principales. Las pequeñas dimensiones de la mayoría de ellas podrían actuar como un limitante del peso que puedan adquirir con respecto a los poderes públicos y al mercado, si bien existen dos elementos que podrían compensar esta carencia: la creciente articulación de estas iniciativas a través de redes locales y supralocales y los apoyos crecientes que van obteniendo por parte de los mismos poderes públicos. 
Figura 4

Importancia de sus objetivos y defensa de derechos sociales

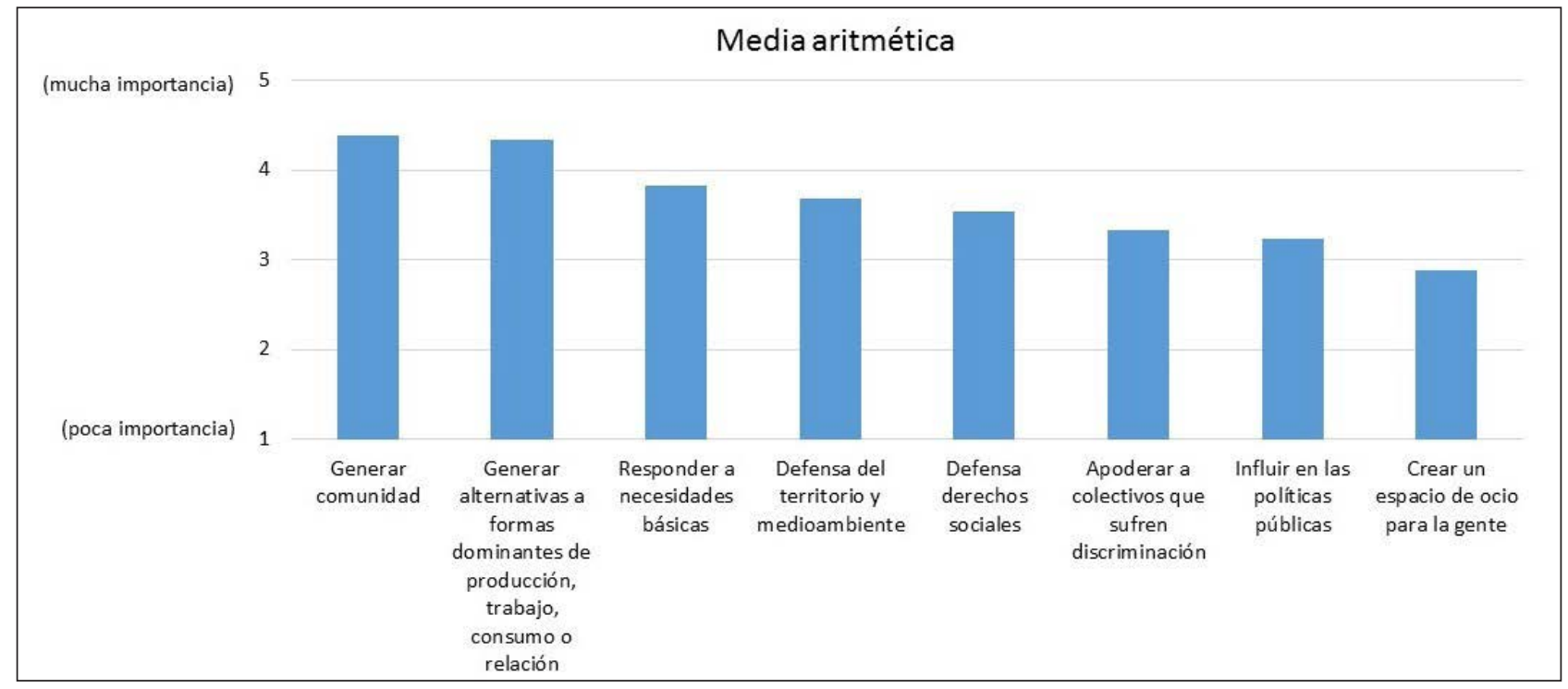

Fuente: Elaboración propia

\section{¿UN FACTOR DE INCLUSIÓN Y DE COHESIÓN SOCIO-ESPACIAL?}

En las nuevas oleadas de movilizaciones ciudadanas, a menudo se ha subrayado que el cómo es tan importante como el qué, expresando la importancia de que las formas organizativas (horizontalidad, transparencia, democracia interna) sean coherentes con los objetivos que se persiguen. Esto nos conduce a pensar si la pregunta sobre el quién ha tenido esa misma notoriedad en la agenda de estas prácticas sociales emergentes. Sin duda, la composición de sus bases sociales y territoriales nos puede ayudar a entenderlas mejor. Saber cuáles son los perfiles sociales de los participantes, quienes las lideran y en qué tipo de territorios se llevan a cabo, nos per- mite situar mejor sus potencialidades, pero también sus limitaciones y retos. En este sentido, la combinación de los datos ya analizados con los resultados de las encuestas y de las entrevistas nos aportan los siguientes resultados.

En cuanto a la distribución por ámbitos regionales, los resultados expresan que ésta es bastante equilibrada. A partir del Mapa de la Innovación Social, observamos que más de un $75 \%$ de las prácticas detectadas se desarrollan en la Región Metropolitana de Barcelona (RMB) (figura 5). De aquí se podría derivar un importante sesgo territorial, pero en realidad este porcentaje es bastante proporcional al peso poblacional de la RMB en comparación con el resto de ámbitos territoriales.

Figura 5

Distribución territorial por ámbitos regionales

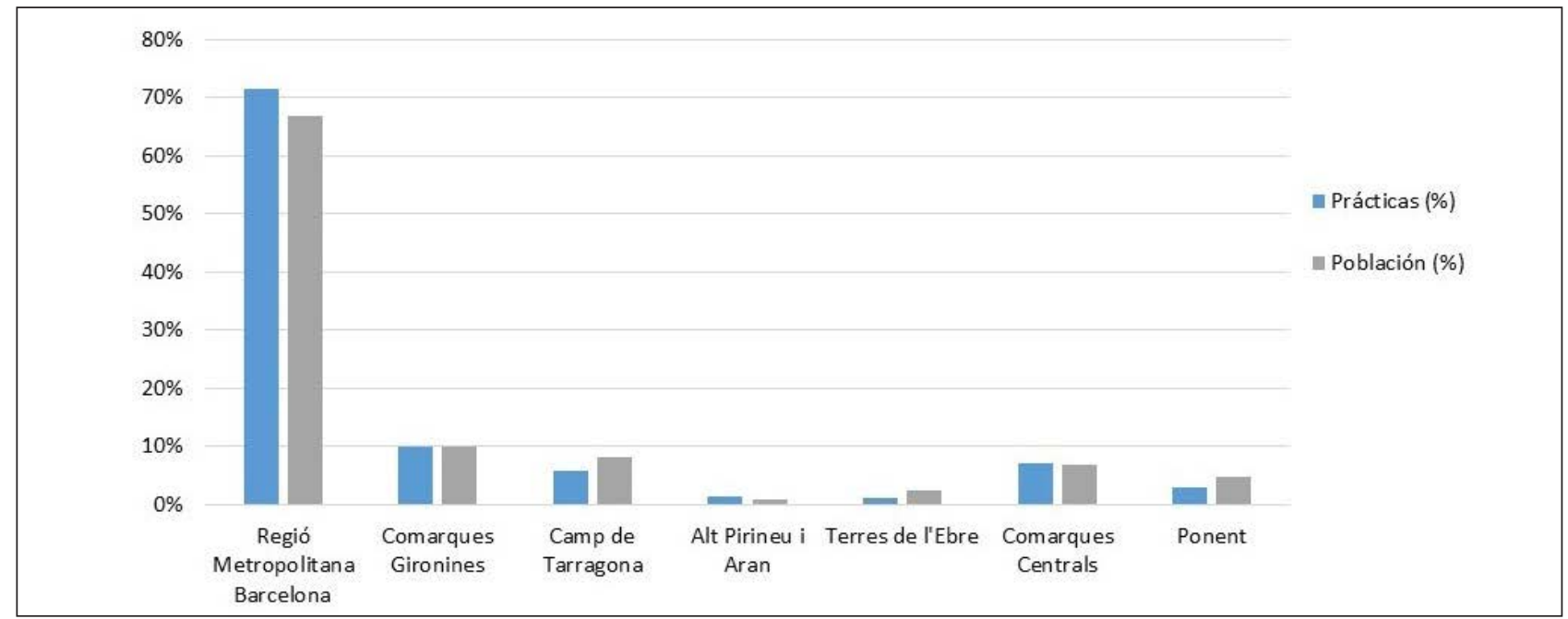

Fuente: Elaboración propia 
Afinando más el análisis, la superposición entre el Mapa de la Innovación Social en Cataluña y los mapas de la segregación urbana (Blanco et al. 2016) nos permite observar las pautas de distribución socio-espacial de la innovación social en función del grado de segregación de los territorios (figura 6).

Este ejercicio nos permite detectar que las prácticas identificadas no se producen en aquellas áreas donde reside la gente con rentas ni más altas ni más bajas. Podríamos inferir de esto que las personas con más recursos no tienen necesidad de innovar socialmente y las que menos tienen no siempre disponen de los recursos (sociales, educativos, económicos...) necesarios para responder de manera autónoma a sus necesidades. Por tanto, aquellos barrios con más dificultades económicas, con un tejido social menos estructurado y que deben orientar todos sus esfuerzos en la cobertura de necesidades básicas, tienen más difícil desarrollar ciertas prácticas de innovación social. En cambio, estos datos nos sugieren que los liderazgos recaen en aquellos segmentos sociales que, si bien no son necesariamente adinerados, disponen de mayores recursos culturales, cognitivos y sociales que les permiten organizarse para intentar satisfacer necesidades comunes o impulsar proyectos alternativos. En una de las entrevistas, un responsable municipal sostenía:

«(...) en algunos de los espacios cedidos bajo el proyecto municipal Pla Buits predomina un perfil social muy concreto: arquitecto/a, clase media cultural con buena calificación universitaria y con red social».
Por otra parte, un activista social que ha participado en espacios de economía social decía durante una entrevista:

«Hay mucha gente en la innovación social que responde a este perfil. O sea, culturalmente es clase media, pero económicamente es clase trabajadora o precaria. Hecha esta puntualización, creo que en general la gente que compone estas prácticas es una mezcla entre clase media económica y clase media cultural».

El estudio también permite detectar que una parte importante de los grupos impulsores de estas iniciativas se muestra muy satisfecha en cuanto a la integración de grupos sociales vulnerables, de personas inmigradas y en lo relativo a la igualdad de género (figura 7). Este último es el criterio en el que las personas participantes en las experiencias muestran un mayor grado de satisfacción (un $50 \%$ valora con "mucha satisfacción" su cumplimiento). Además, en relación con los retos que afrontan estos colectivos, el aumento de la diversidad social en la composición del colectivo no es uno de los señalados como más relevantes. Si hay una satisfacción con la composición diversa del grupo, parece lógico que no sea señalado como reto de futuro.

Los datos cuantitativos y cualitativos recogidos indican, pues, que la innovación social acostumbra a impulsarse desde grupos de clase media, si bien aquello que les caracteriza no es tanto su nivel de renta como su estatus socioeducativo. Sea como fuere, la necesidad parece ser un factor necesario para el impulso de procesos de innovación social, pero no es suficiente.

\section{Figura 6}

Intensidad de segregación urbana vs. localización de prácticas de innovación social (Región Metropolitana de Barcelona)

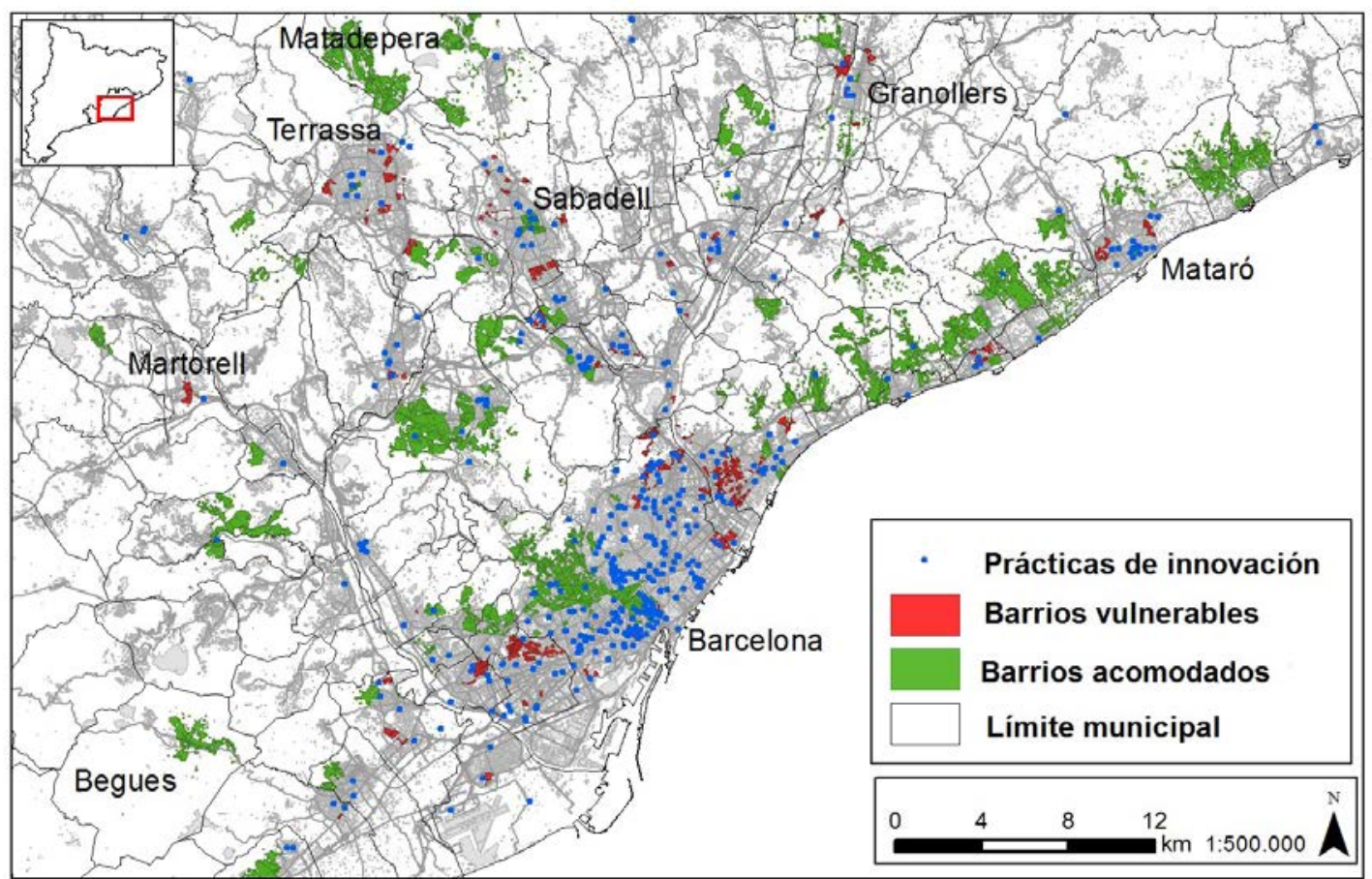

Fuente: Elaboración propia 
Figura 7

Satisfacción de criterios y retos

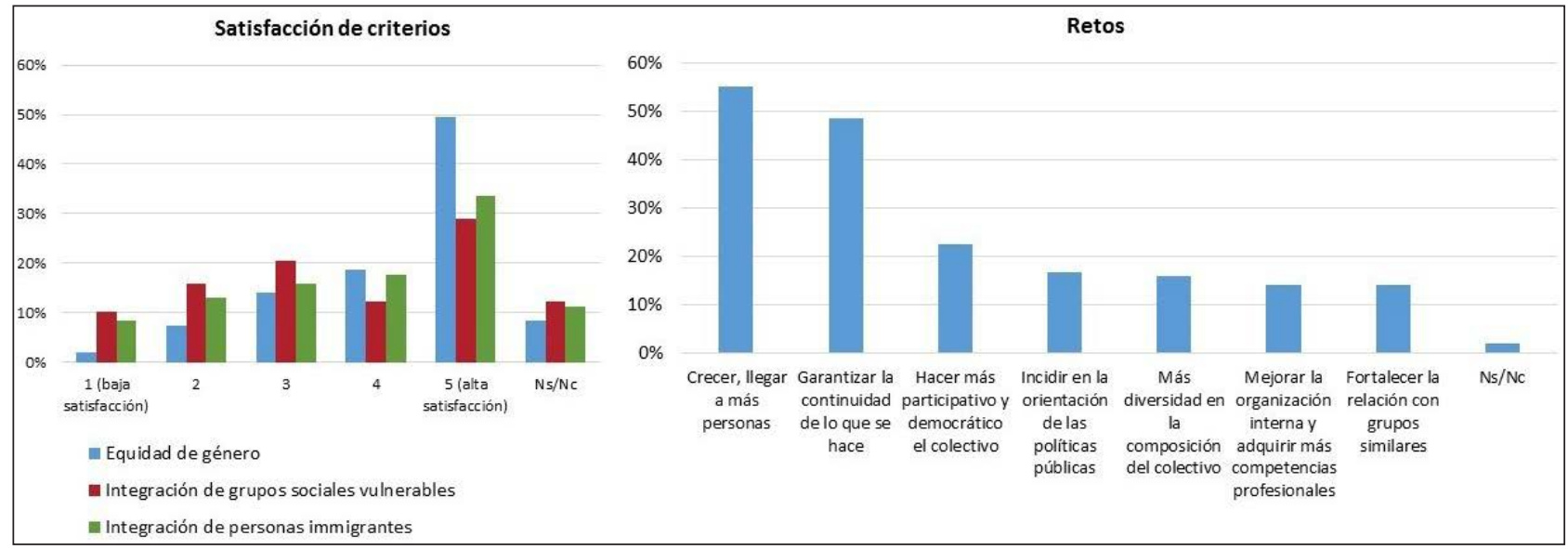

Fuente: Elaboración propia

\section{¿Hacia UnA NUEVA INSTITUCIONALIDAd DE- MOCRÁTICA?}

El potencial de las iniciativas de innovación social para construir nuevas arquitecturas institucionales capaces de activar, reforzar y ampliar derechos sociales y de ciudadanía depende fundamentalmente de tres tipos de factores: las propias características organizativas de las iniciativas (en especial, su carácter más o menos participativo); la sostenibilidad de las experiencias (su autonomía financiera y el grado de profesionalización de sus integrantes), y la escalabilidad, como consecuencia de su capacidad de articulación intra e intersectorial.

Con respecto a la organización interna, el $80 \%$ de las iniciativas afirma tener mecanismos para garantizar la participación de sus miembros en la toma de decisiones. En el $45 \%$ de las prácticas estos mecanismos tienen forma de asamblea, mientras que el $55 \%$ también dispone de otros mecanismos participativos. Por tanto, son experiencias con un fuerte carácter participativo a nivel interno. Sin embargo, las entrevistas señalan que el debate sobre la organización interna está abierto y se puede considerar como uno de los retos políticos más significativos. Tal y como señala uno de los activistas entrevistados:

«Otro reto es el desarrollo de una cultura organizativa potente. Por ejemplo, que seamos capaces de hacer buenas reuniones y asambleas, con capacidad de tomar decisiones colectivamente. (...) Se trata de saber cómo organizar, cómo tener una mirada sobre formas de funcionar que dejan fuera a gente porque no tienen la capacidad económica o el tiempo para hacerlo».

La existencia de estructuras participativas, por tanto, no es necesariamente garantía de un funcionamiento adecuado. La asistencia a los espacios participativos puede ser muy baja y, además, muy desigual, algo que requiere, según alguno de nuestros entrevistados, reflexionar sobre los distintos ro- les que las personas pueden adoptar en las diversas experiencias en las que participan:

«Hay que tener presente la regla del $1 \%, 9 \%, 90$ $\%$ : no podemos pretender ser el $1 \%$ súper activo en todas las iniciativas de las que formamos parte, porque sería imposible; en algunas iniciativas podemos ser parte de este $1 \%$; en otras iniciativas podemos ser parte del $9 \%$ que tiene una mayor implicación sin estar siempre presente, y en muchas otras podemos ser parte del $90 \%$ que participa solamente de manera esporádica».

La cuestión de la organización y participación no es sólo relevante a escala interna, sino que a nivel externo también presenta algunos retos. Hablamos de las relaciones interorganizativas. De la encuesta se desprende que quienes participan en este tipo de experiencias tienen relaciones frecuentes con otros colectivos. El $60 \%$ pertenece a una red de entidades. Más del $50 \%$ se reúne al menos una vez al mes con otros grupos (la mayoría, más del $60 \%$, de la misma localidad). A pesar de ello, las personas entrevistadas alertan de que la interconexión entre las experiencias es lo que debe permitir dar el salto de escala. Este tipo de prácticas son espacios que:

«(...) más allá de su efecto inmediato, han de estimular la organización ciudadana y que las futuras demandas sociales puedan escalar (...) muchos de los problemas no se pueden solucionar a escala ciudad. La desigualdad no la puedes combatir a nivel de barrio o ciudad. Hablamos de escala europea. Las innovaciones sociales transformadoras pueden ser tiritas si no hay manera de conectarlas y producir escala de resistencia».

En definitiva, mientras no haya algún tipo de elemento que articule las prácticas de innovación social,

«(...) seguirán existiendo pero no se estructurará como una propuesta de cambio macrosocial, nos quedaremos a nivel microsocial».

Retomando la cuestión de las relaciones entre estas prácticas y otros sectores (públicos, privados 
y asociativos), cabe recordar que el $66 \%$ se definen como "exclusivamente ciudadanas". El mismo porcentaje reconoce no tener ningún tipo de apoyo significativo por parte de las entidades del tercer sector.

Respecto a la presencia de estas iniciativas en el mercado, las entrevistas nos aportan reflexiones sobre este tema, existiendo dos grandes visiones. Por un lado, hay quien enfatiza el riesgo de cooptación, de modo que el mercado, al tener una base económica más sólida, acaba apropiándose de las prácticas de innovación social, desvirtuando su sentido original. Como lo expresan algunos entrevistados desde el ámbito académico:

«La innovación social se puede hacer servir para cooptar prácticas que se producen gracias a interacciones no monetarias. Con el discurso más convencional del 'emprendimiento social' las instituciones públicas convierten en competitivos este tipo de procesos, que pueden convertirse en servicios a bajo coste para responder a demandas sociales. Es el caso del proyecto Big Society en el Reino Unido».

En cambio, hay otra perspectiva que ve al mercado como una oportunidad que puede reforzar y contribuir a escalar estas iniciativas, tal y como ha sucedido con diferentes prácticas en el campo de la economía colaborativa.

En cuanto a las relaciones con las administraciones, la mayoría remarcan su carácter autogestionario (figura 8). Sin embargo, sólo un $35 \%$ sostiene que no recibe ningún apoyo de la Administración o muy poco, lo que nos indica que, si bien hablamos de experiencias con un fuerte protagonismo social y con un elevado grado de autonomía, las relaciones con la administración pública existen y, para más de un tercio, el apoyo que reciben es significativo.

El mayor apoyo institucional que reciben estas iniciativas procede de la Administración local. La relación con las escalas administrativas más amplias, por el contrario, es prácticamente inexistente. Llama la atención la ausencia de apoyo de la UE, a pesar del énfasis que esta institución ha puesto en la cuestión de la innovación social durante la última década. La UE, por tanto, puede estar contribuyendo a generar un marco conceptual y político de referencia para las políticas de promoción de la innovación social, pero cuando las iniciativas cooperativas buscan apoyos institucionales no recurren a este nivel, sino que lo hacen a otros más cercanos, principalmente los del ámbito municipal.

Los datos nos indican que el apoyo que se busca de las administraciones es, principalmente, la cesión de espacios donde desarrollar proyectos, seguida de la adopción de marcos legislativos adecuados a sus especificidades (figura 9). Un técnico municipal del área de participación del Ayuntamiento de Barcelona amplía esta cuestión incidiendo en los procedimientos institucionales:

«El reto para la Administración es innovar en el procedimiento. Toda la maquinaria administrativa debe poder facilitar que estas entidades ciudadanas lleven a cabo estos proyectos. Innovar en el procedimiento administrativo es una condición para innovar en los reglamentos».

Significativamente, las ayudas y subvenciones públicas son señaladas como prioritarias para un $25 \%$ de las experiencias consultadas, mientras que más del $20 \%$ sostiene que, en realidad, deberían desarrollarse con plena autonomía respecto a las administraciones públicas.

La reivindicación de espacios y de adaptaciones legislativas por parte del sector público redunda en la vocación de autonomía de estas iniciativas. Sin embargo, las personas entrevistadas remarcan que este aspecto no puede ser una excusa para el retroceso del sector público. Por un lado, como indica uno de los investigadores consultados:

«Las instituciones públicas deben ser facilitadoras (...). El rol de la administración pública no puede ser directivo. Es presuntuoso pensar que es la institución quien debe dirigir. Más bien tienes que crear hubs de innovación, espacios donde la gente pueda reunirse y dar recursos para difundir».

\section{Figura 8}

Grado de relación con las administraciones

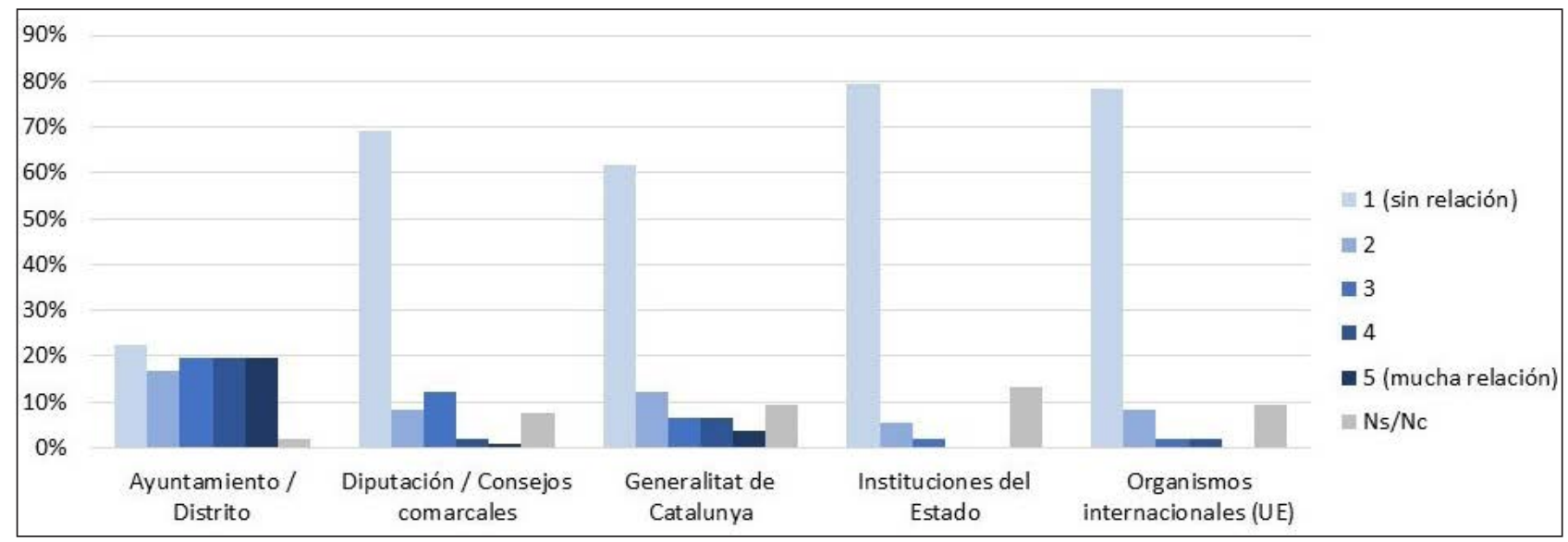

Fuente: Elaboración propia 
Figura 9

Expectativas de apoyo institucional

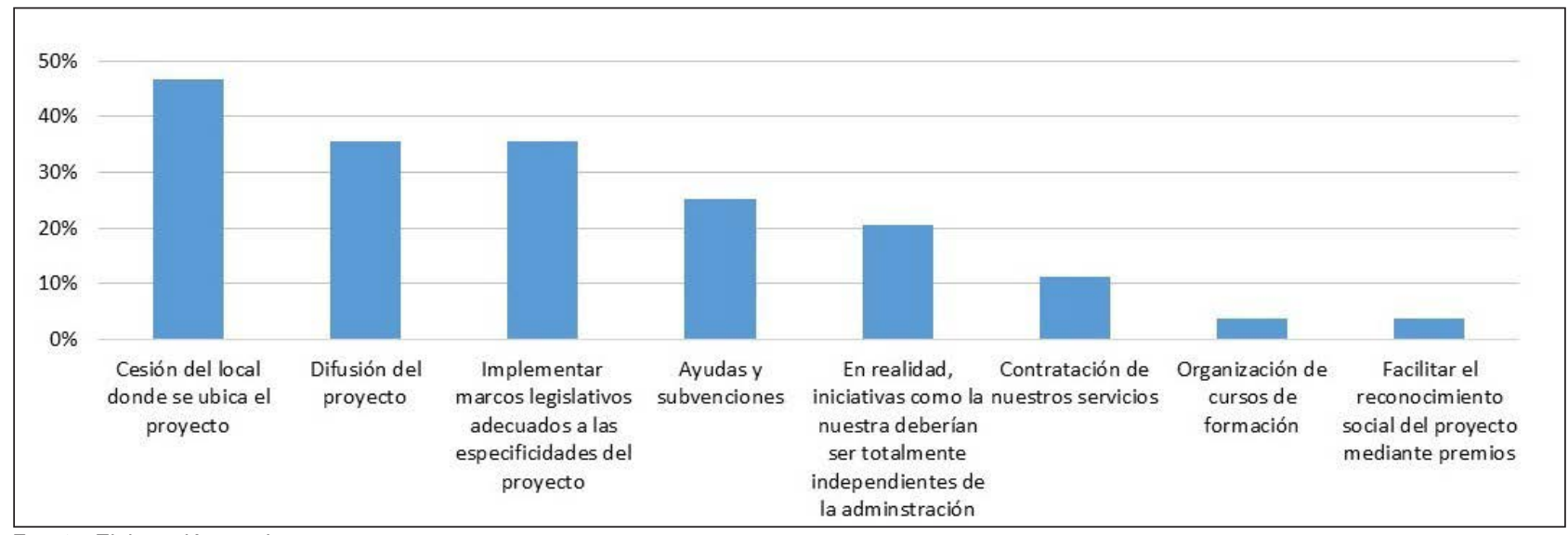

Fuente: Elaboración propia

Por otro lado, hay quien relativiza el papel de la innovación social frente a los poderes públicos, ya que:

«Por mucho que estemos encima del tema de la autogestión, el Estado es la forma más efectiva de satisfacer necesidades colectivas. La autogestión como máxima puede venir de la extrema izquierda o de un modelo de gestión neoliberal. La autogestión como modelo puede funcionar como el libre mercado, excluyendo de la garantía de cobertura de necesidades básicas a los que menos recursos tienen».

\section{Conclusiones principales}

Tras el análisis de los datos empíricos podemos retomar las tres preguntas principales que son objeto de este artículo y señalar la relevancia de los resultados obtenidos en contraste con la literatura internacional sobre la innovación social.

En primer lugar, sobre la autonomía de estas iniciativas. En investigaciones que han analizado la operatividad de la innovación social de forma similiar, los casos de estudio percibían "la financiación pública como su principal contribución" (Martinelli, Moulaert y González 2010). Esta dependencia ha provocado que los cambios en las formas de financiación (reducción de partidas asignadas, uso de indicadores económicos, penetración de los principios del New Public Management) haya tenido impactos sobre la sostenibilidad de los proyectos e incluso sobre los vínculos comunitarios y de solidaridad que sostenían estas prácticas (ibid.). Lo que nos encontramos en nuestra investigación puede ser interpretado como una reacción crítica a estos procesos de dependencia. Por un lado, las prácticas analizadas expresan una fuerte vocación de ser autónomas: en su mayoría aluden a un origen exclusivamente ciudadano y a la necesidad de tener como objetivo sostener la comunidad. Por otro lado, establecen relaciones con instituciones públicas, pero buscando que no determinen sus objetivos y formas de funcionamiento. Por tanto, no nos encontramos con una noción de auto- nomía como negación del papel de las instituciones públicas, sino como forma de evitar dependencias que pongan en peligro la sostenibilidad del proyecto y de la comunidad que lo conforma.

En segundo lugar, sobre la capacidad para generar dinámicas de empoderamiento ciudadano. La literatura sobre innovación social que entiende las variables socio-espaciales y la acción de grupos vulnerables como elementos centrales en su enfoque nos ofrece algunas reflexiones que es interesante comparar con lo hasta aquí expuesto. Si bien se ha hecho especial énfasis en la innovación social como proceso para responder a necesidades básicas a través de la acción de grupos vulnerables para producir cambios en las relaciones de poder (González, Moulaert y Martinelli 2010), hay elementos relevantes que permanecen sin analizar. Como se señala, muchos de los casos examinados hacen referencia a la movilización voluntaria de grupos sociales vulnerables agregando diferentes fuerzas sociales alrededor de un mismo objetivo, a veces con el apoyo de organizadores profesionales o líderes locales (ibid.).

A partir de estas ideas y del trabajo empírico realizado, se hace necesario pensar en la composición social de estas prácticas. La metodología cartográfica empleada, basada en el contraste entre las pautas de distribución territorial de la innovación social y las dinámicas de segregación socio-espacial, nos permite enfatizar en una idea habitualmente desconsiderada en otras investigaciones basadas en estudios de caso, a saber: que no innova quien más padece la crisis o quien más lo necesita, sino quienes, sobre todo, tienen más recursos para poder organizarse. Las iniciativas se concentran en los territorios donde viven personas con perfiles que, si bien han padecido la crisis, también tienen recursos cognitivos, culturales y organizativos para construir respuestas. La capacidad de acción colectiva, significativamente condicionada por los recursos socioeconómicos y sobre todo socioeducativos, parece ser un factor de gran importancia para 
la innovación social. Consideramos que tales observaciones requieren ser tenidas muy en cuenta al valorar el potencial de la innovación social en tanto que estrategia de empoderamiento de los colectivos y en los territorios más vulnerables. La escasa reflexión crítica observada entre los colectivos que protagonizan las prácticas resulta, en este contexto, preocupante.

En tercer y último lugar, la capacidad de las iniciativas socialmente innovadoras de generar nueva institucionalidad democrática. Sobre esto, es interesante recoger algunos elementos del trabajo realizado por Elinor Ostrom en sus investigaciones sobre instituciones de acción colectiva. Ostrom (1990) sistematiza los patrones de funcionamiento de recursos gestionados comunitariamente a través de una serie de principios de diseño que aluden a elementos democráticos: los principios de transparencia, las sanciones por el mal uso del recurso, los mecanismos de resolución de conflictos, la posibilidad de cambiar las reglas, el acceso a la información para participar en el autogobierno, etc. Una de las conclusiones que se extraen de estas investigaciones es que este conjunto de normas refuerza la eficiencia y la eficacia de estas prácticas comunitarias. Este diseño institucional es lo que ha hecho posible que estas prácticas comunales se mantengan en en el tiempo. Por tanto, la propia experimentación con formas institucionales de acción colectiva puede ser un espacio para modelar e intentar escalar, a través de instituciones anidadas, nuevas formas de resolución de problemas colectivos.

Para analizar estas dinámicas de experimentación institucional hemos observado las características organizativas y la cultura participativa de las iniciativas sociales, la sostenibilidad de las experiencias (tanto su autonomía financiera como el grado de profesionalización de sus integrantes) y la capacidad para generar redes densas que permitan hacer escalar estas prácticas. Hemos visto que, si bien se autodefinen con un alto grado de cultura participativa, éste es un elemento en continuo debate. Las propias dinámicas internas y las inercias de reconocimiento entre actores de cada campo social pueden llegar a normalizar formas de exclusión sobre otros segmentos sociales, ya sea por su origen migratorio, su condición de clase o de género. El esfuerzo colectivo y el compromiso necesarios para sostener este tipo de prácticas hace a veces difícil que los propios actores detecten la carencia de algunos mecanismos democráticos.
Vemos, en definitiva, que, al observar en profundidad las dinámicas de innovación sobre el territorio, estos tres elementos que aparecen en la literatura (autonomía, empoderamiento, institucionalidad democrática) toman un carácter crítico. La autonomía pasa a formar parte de una búsqueda de estabilidad por parte de las comunidades que protagonizan la innovación social y no tanto una estrategia de éxodo de la trama institucional. La innovación social, como proceso de empoderamiento de los grupos sociales más afectados por la crisis, depende de prácticas de alianza social (como ocurre en la PAH) con aquellos segmentos que tienen más recursos socioeducativos para producir respuestas y, también, de la labor de promoción y de apoyo de las innovaciones sociales que las instituciones puedan hacer en las comunidades más vulnerables. Las prácticas de experimentación institucional están atravesadas por elementos de innovación democrática, pero también por ciertas carencias en términos de inclusión social, acceso abierto a la toma de decisiones, consolidación en el tiempo y escalabilidad. De nuevo, consideramos que las instituciones públicas pueden jugar un papel crítico en la garantía de todos estos aspectos.

Nuestra investigación, en definitiva, apunta hacia una paradoja fundamental en los procesos de innovación social: si bien dichos procesos emergen en parte como respuesta a una crisis con una fuerte componente institucional, tratando de configurar respuestas sociales alternativas a las ofrecidas por las instituciones públicas dominantes, la propia emergencia, expansión y consolidación de las innovaciones sociales requiere, en buena medida, del apoyo por parte de las mismas instituciones públicas. Esta paradoja es fuente de tensiones y contradicciones constantes en la práctica de la innovación social y representa, a nuestro entender, un campo fundamental de reflexión teórica e investigación empírica en este terreno.

\section{Agradecimientos}

Esta investigación ha recibido el apoyo del Programa RecerCaixa [Referencia 2012ACUP00004] y del Programa de Innovación y Calidad Democrática de la AGAUR y el Departament de Governació i Relacions Institucionals de la Generalitat de Catalunya [Referencia 2014DEMOC00024].

\section{NOTAS}

1. El Consejo Europeo extraordinario de Lisboa (2000): hacia la Europa de la innovación y el conocimiento. http://europa.eu/legislation_summaries/education_training_youth/general_framework/c10241_es.htm

2. Ver link mapa http://barrisinnovacio.net/mapa/

3. https://obamawhitehouse.archives.gov/administration/ eop/sicp

4. https://esdp-network.net/research-collaborations/projects/singocom

5. Ver link formulario colaborativo http://barrisinnovacio. net/mapa/

6. Ver link web http://barrisinnovacio.net

7. Para más detalles sobre los bancos del tiempo, su dimensión social y la relación con el $15 \mathrm{M}$ ver Valor y Papaoikonomou (2016).

8. Sobre el rol de los activistas tecnológicos, la importancia de internet en el $15 \mathrm{M}$ y la innovación democrática, ver Romanos y Sádaba (2016). 


\section{ReferenCias BibLIOGRÁficas}

Andreu, M. 2015. Barris, veïns i democràcia. El moviment ciutadà i la reconstrucció de Barcelona. Barcelona: L'Avenç.

Blanco, I., S. Fleury y J. Subirats. 2012. "Nuevas miradas sobre viejos problemas: periferias urbanas y transformación social". Gestión y Política Pública 21:3-40. Consulta 8 de octubre de 2016 (https://dialnet.unirioja.es/ servlet/articulo?codigo $=5370639$ )

Blanco, I., H. Cruz Gallach, R. Martínez y M. Parés. 2016. "EI papel de la innovación social frente a la crisis". Ciudad y territorio: estudios territoriales 188: 249-260. Consulta 1 de octubre de 2016 (https://apps.fomento.gob.es/ CVP/handlers/pdfhandler.ashx?idpub=BP1016)

Brugué, Q., I. Blanco y J. Boada. 2014. "Entornos y motores para la innovación en las políticas públicas". Revista del CLAD Reforma y Democracia 59:7-34.

Bureau of European Policy Advisors (BEPA). 2010. Empowering People, Driving Change. Social Innovation in European Union. European Commission. Consulta 14 de noviembre 2016 (https://ec.europa.eu/migrant-integration/librarydoc/empowering-people-driving-changesocial-innovation-in-the-european-union)

Conejero, E. y J.C. Redondo. 2016. "La innovación social desde el ámbito público: conceptos, experiencias y obstáculos". GAPP 15: 23-42. http://dx.doi.org/10.24965/ gapp.v0i15.10310

Dalmau, M. e I. Miró. 2013. Les Cooperatives Obreres de Sants. Autogestió proletària en un barri de Barcelona (1870-1939). Barcelona: La Ciutat Invisible Edicions.

Godin, B. 2008. "Innovation. The History of a category". Working paper No. 1. Project on the Intellectual History of Innovation. Montreal. Consulta 11 de noviembre 2016 (http://www.csiic.ca/PDF/IntellectualNo1.pdf)

González, S., F. Moulaert y F. Martinelli. 2010. "ALMOIN: How to analyse social innovation at the local level?". Pp. 49-67 en Can neighbourhoods save the city? Community Development and Social Innovation, editado por F. Moulaert, F. Martinelli, E. Swyngedouw y S. González. London: Routledge.

Leadbeater, Ch. 1997. The rise of the social entrepreneur. London: NESTA.

Martinelli, F. 2013. "Learning from case studies of social innovation in the field of social services: creatively balancing top-down universalism with bottom-up democracy". Pp. 346-360 en The International Handbook on Social Innovation, editado por F. Moulaert, D. MacCallum, A. Mehmood y A. Hamdouch. Cheltenham: Edward Elgar Publishing. https://doi.org/10.4337/9781849809986.00044

Martinelli, F., F. Moulaert y S. González. 2010. "Creatively designing urban futures: a transversal analysis of socially innovative initiatives". Pp. 198-218 en Can neighbourhoods save the city? Community Development and Social Innovation, editado por F. Moulaert, F. Martinelli, E. Swyngedouw y S. González. London: Routledge.

Martínez Celorrio, X. 2015 "La Innovación social frente a los desafíos del bienestar". Pp. 541-569 en Informe España 2015. Madrid: Fundación Encuentro.

Moulaert, F. 2010. "Social innovation and community development: concepts, theories and challenges". Pp. 4-16 en Can neighbourhoods save the city? Community Development and Social Innovation, editado por F. Moulaert, F. Martinelli, E. Swyngedouw y S. González. London: Routledge.

Mulgan, G. 2006. "The Process of Social Innovation". Innovations: Technology, Governance, Globalizations 1 (2): 145-162. https://doi.org/10.1162/itgg.2006.1.2.145

Murray, R., J. Caulier-Grice y G. Mulgan. (2010). The Open Book of Social Innovation. Social Innovator Series: ways to design, develop and grow social innovation. The Young Foundation \& NESTA.

NESTA. 2006. The Innovation Gap. Londres: Nesta Research Report. Consulta 2 de noviembre 2016 (http://www. nesta.org.uk/publications/innovation-gap)

NESTA. 2007. Hidden Innovation. Londres: Nesta Research Report. Consulta 2 de noviembre 2016 (http://www. nesta.org.uk/publications/hidden-innovation)

Observatorio Metropolitano de Barcelona (OMB). 2013. "Comunes urbanos en Barcelona. Prácticas de defensa, cuidado, reapropiación y gestión comunitaria". BarceIona: OMB Ed. Consulta 5 de noviembre 2016 (http:// bcncomuns.net/es/resultados/)

OECD. 1997. Os/o Manual: Proposed Guidelines for Collecting and Interpreting Technological Innovation. Paris: OECD Publishing.

OECD. 2005. Oslo Manual: Guidelines for Collecting and Interpreting Innovation Data ( $3^{\mathrm{a}}$ ed.). Paris: OECD Publishing.

Oosterlynck, S., Y. Kazepov, A. Novy, P. Cools, E. Barberis, F. Wukovitsch, T. Saruis y B. Leubolt. 2013. The butterfly and the elephant: local social innovation, the welfare state and new poverty dynamics. ImPRovE Discussion Paper 13/03. Antwerp: Herman Deleeck Centre for Social Policy - University of Antwerp. Consulta 19 de enero 2015 (http://improve-research.eu).

Ostrom, E. 1990. Governing the commons. The Evolution of Institutions for Collective Action. Cambridge: Cambridge University Press. https://doi.org/10.1017/ CBO9780511807763

Romanos, E. e I. Sádaba. 2016. "From the Street to Institutions through the App: Digitally Enabled Political Outcomes of the Spanish Indignados Movement". Revista Internacional de Sociología 74(4): e048. http://dx.doi. org/10.3989/ris.2016.74.4.048

Schumpeter, J. A. 1934. The Theory of Economic Development. New Brunswick: Transaction Publishers.

Snow, D. 2004. "Social movements as challenges to authority: Resistance to an emerging conceptual hegemony". Pp. 3-25 en Research in Social Movements, Conflicts and Change (vol. 25). https://doi.org/10.1016/S0163786X\%2804\%2925001-7

Stirling, A. 2015. "From Knowledge Economy to Innovation Democracy". Sussex: ESRC STEPS. Consulta 14 de septiembre 2016. https://doi.org/10.13140/ RG.2.1.1395.0801

Tilly, Ch. 1978. From mobilization to revolution. Reading, MA: Addison-Wesley.

Valor, C. y E. Papaoikonomou. 2016. "Time banking in Spain. Exploring their structure, management and users' profile". Revista Internacional de Sociología 74 (1): e028. https://doi.org/10.3989/ris.2016.74.1.028 
RUBÉN MARTÍNEZ MORENO es miembro y co-fundador de la Hidra Cooperativa, cooperativa de trabajo asociado dedicada a la investigación social aplicada y al análisis de la economía urbana. Miembro de la red estatal Fundación de los Comunes. Doctor en Ciencia Política y Políticas Públicas por el Instituto de Gobierno y Políticas Públicas (IGOP) de la Universitat Autònoma de Barcelona (UAB). Licenciado en Bellas Artes (Universitat de Barcelona) y máster en Ciencias Políticas y Transformación Social (UAB). Ha participado como investigador en proyectos europeos como TRANSGOB centrado en el estudio de la gobernanza urbana en Reino Unido y España y en la investigación P2PValue sobre gobernanza comunitaria en la red.

HELENA CRUZ GALLACH es doctora en Geografía por la Universitat Autònoma de Barcelona y máster en Gestión Urbana por la Erasmus Universiteit Rotterdam. Actualmente es investigadora en el IGOP y en el Instituto de Estudios Regionales y Metropolitanos de Barcelona (IERMB). Especializada en ordenación y planificación del territorio, sus ámbitos de interés son la gobernanza y la participación ciudadana en las políticas urbanas, la conflictividad territorial en la planificación urbanística y las formas de empoderamiento en la gestión del espacio público. Forma parte de los grupos de investigación URGOCIS (IGOP-UAB) y Espais Crítics (UB). Anteriormente ha sido investigadora postdoctoral en el Departamento de Geografía de la UAB, docente en la Escola Universitària de Turisme Mediterrani (centro adscrito a la Universitat de Girona) e investigadora invitada en la University of California de Los Angeles, el Istituto Universitario di Architettura di Venezia, la National University of Ireland Maynooth y la Università Ca' Foscari.

ISMAEL BLANCO es doctor en Ciencia Política por la Universitat Autònoma de Barcelona. Investigador en el IGOP y profesor agregado en el Departamento de Ciencia Política y Derecho Público de la UAB. Como investigador Ramón y Cajal ha estado vinculado al Departamento de Ciencias Políticas y Sociales de la Universitat Pompeu Fabra. Ha sido investigador Beatriu de Pinós en el Departamento de Políticas Públicas de la De Montfort University (Reino Unido) e investigador visitante en la Universitat Federal de Minas Gerais y la Fundación Joao Pinheiro (Brasil). Es miembro del grupo de investigación URGOCIS del IGOP. Sus investigaciones actuales se centran en los impactos socio-espaciales de la crisis en las ciudades y en las formas emergentes de participación y de gobernanza en este contexto. Ha sido miembro del consorcio de investigación Collaborative Governance Under Austerity: An Eight-Case Comparison, financiado por el Economic and Social Research Council (Reino Unido).

YUNAILIS SALAZAR es doctoranda en Ciencias Políticas, Políticas Públicas y Relaciones Internacionales (IGOP-UAB) Licenciada en Ciencias Políticas y Administrativas de la Universidad Central de Venezuela, máster en Políticas Sociales y Mediación Comunitaria (IGOP-UAB) y máster en Gestión Pública (UAB-UB-UPF). Forma parte del grupo de investigación URGOCIS del IGOP. Sus intereses de investigación se orientan hacia el campo de la gestión pública y las políticas urbanas, la gobernanza de las ciudades, la participación comunitaria y la implementación de la contratación pública socialmente responsable en los gobiernos locales. 